\title{
The young Van Dyck's fingerprint: a technical approach to assess the authenticity of a disputed painting
}

\author{
Astrid Harth ${ }^{1,2^{*}} \mathbb{D}$, Geert Van der Snickt ${ }^{3}$, Olivier Schalm² ${ }^{2}$ Koen Janssens ${ }^{3}$ and Griet Blanckaert ${ }^{2}$
}

\begin{abstract}
The painting Saint Jerome, part of the collection of the Maagdenhuis Museum (Antwerp, Belgium), is attributed to the young Anthony van Dyck (1613-1621) with reservations. The painting displays remarkable compositional and iconographic similarities with two early Van Dyck works (1618-1620) now in Museum Boijmans van Beuningen (Rotterdam) and Nationalmuseum (Stockholm). Despite these similarities, previous art historical research did not result in a clear attribution to this master. In this study, the work's authenticity as a young Van Dyck painting was assessed from a technical perspective by employing a twofold approach. First, technical information on Van Dyck's materials and techniques, here identified as his fingerprint, were defined based on a literature review. Second, the materials and techniques of the questioned Saint Jerome painting were characterized by using complementary imaging techniques: infrared reflectography, X-ray radiography and macro X-ray fluorescence scanning. The insights from this non-invasive research were supplemented with analysis of a limited number of cross-sections by means of field emission scanning electron microscopy coupled with energy dispersive X-ray spectroscopy. The results demonstrated that the questioned painting's materials and techniques deviate from Van Dyck's fingerprint, thus making the authorship of this master very unlikely.
\end{abstract}

Keywords: Anthony van Dyck, Saint Jerome, Attribution problems, IRR, XRR, MA-XRF scanning, FE-SEM-EDX

\section{Background}

Over the past decades, technical study of artworks has become increasingly important to address attribution problems. Both the scarcity of documentary evidence about Old Masters' art production as well as their ubiquitous practice of copying and stylistic imitation have prompted art historians to search for clues in the paint itself $[1,2]$. Although imaging and analytical tools have opened up new research avenues to re-evaluate accepted attributions and assess questionable attributions, conducting technical research to address attribution problems remains challenging [3-5]. In order to avoid premature conclusions, a substantial body of reference information on painters' materials and techniques,

\footnotetext{
*Correspondence: astrid.harth@ugent.be

${ }^{1}$ Department of Art, Music and Theatre Sciences, Ghent University Research Foundation Flanders, St-Pietersnieuwstraat 41 B4, 9000 Ghent, Belgium

Full list of author information is available at the end of the article
}

representing the master's entire career, is necessary [6, 7]. Hence, the assessment of attribution problems from a technical perspective has to be twofold. First, a master's fingerprint has to be defined either by studying a relevant corpus of artworks and/or by collecting this information from literature. Second, the goal is to characterize the disputed painting's materials and techniques and benchmark these with the acquired fingerprint.

In this article, we investigated a specific attribution problem by adopting said twofold approach on a contended Van Dyck painting, depicting Saint Jerome with an angel (Fig. 1a). This work entered the collection of the Antwerp Maagdenhuis Museum in 1884. The painting is characterized by a stirring history of attributions; it has been alternately linked to the seventeenth-century Antwerp masters Adam van Noort, Peter Paul Rubens, Gaspar de Crayer and Anthony van Dyck [8]. Today, the painting is ascribed to the young Van Dyck with reservations based on an earlier ascription made by Lodewijk 


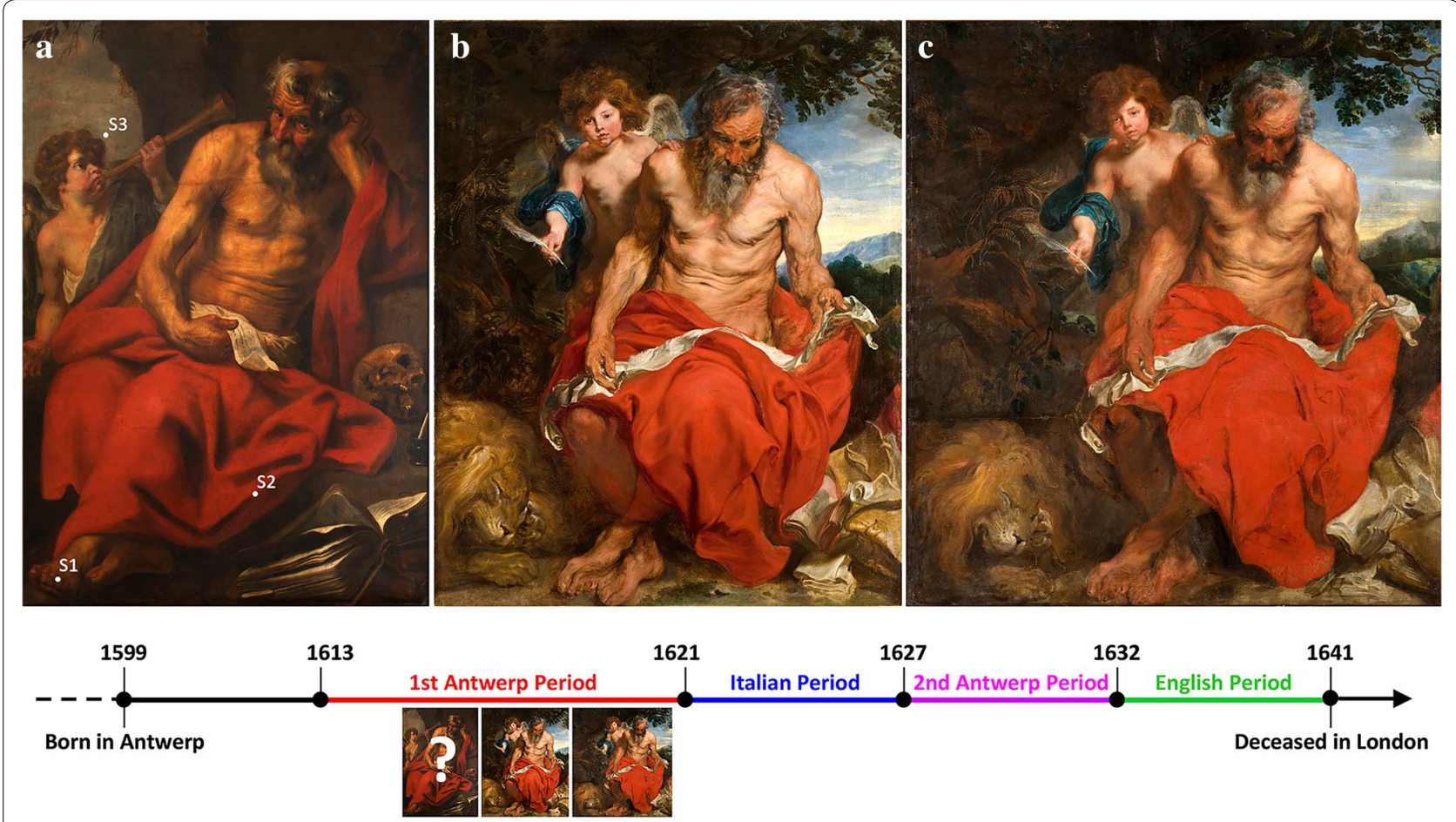

Fig. 1 Composite image of the three Saint Jerome paintings with stylistic and iconographic affinities, accompanied by a timeline indicating Van Dyck's four working periods; a the painting under study: Anthony van Dyck (attributed to), Saint Jerome, 1613-1621, oil on canvas, $148 \times 108 \mathrm{~cm}$, Maagdenhuis Museum, Antwerp, photograph by Oswald Pauwels, Artesis Hogeschool, with annotation of three sample locations; b Anthony van Dyck, Saint Jerome with an Angel, 1618-1620, oil on canvas, $165 \times 130$ cm, Boijmans van Beuningen, Rotterdam; c Anthony van Dyck, Saint Jerome with an Angel, 1618-1620, oil on canvas, $167 \times 154$ cm, Nationalmuseum, Stockholm, photograph by Erik Cornelius, Nationalmuseum (CC BY SA)

Philippen in 1933 [9]. Anthony van Dyck (1599-1641) was an Antwerp Baroque painter, who had a short but prolific international career working in Flanders, Italy and England [10]. Philippen identified the artwork as by the hand of this master based on its significant iconographic and compositional resemblances with two early authentic paintings (Fig. 1b, c). The uncommon iconographic subject recalls Van Dyck's artistic production during his formative years in Antwerp, the so-called First Antwerp Period (1613-1621). In fact, based on his surviving oeuvre, Van Dyck was only then fascinated by this unusual iconographic theme, while, during his following working periods in Italy (1621-1627), Flanders (16271632), and England (1632-1641) (see Fig. 1), the artist never seemed to return to the Saint Jerome with an angel [10-12].

Currently, the absence of documentary evidence on the painting's provenance and its problematic state of preservation impedes art historical research to evaluate the artwork's questioned attribution to the young Van Dyck. Particularly, the physical alterations of the paint surface mainly caused by discolored varnish, retouches and overpaints as well as over-cleaning areas and paint losses, made it difficult to discern the artwork's original artistic quality. Because in-depth stylistic research was ruled out, technical examination was anticipated to offer new possibilities for the evaluation of the painting's authenticity as being a work by the young Anthony van Dyck.

\section{Experimental}

The disputed painting's materials and techniques were studied by combining imaging and analytical methods. The composition and structure of the painting's canvas support were characterized through visual observation of the weave pattern and thread density, and observation of the textile fibers by optical microscopy (OM). The underdrawing was revealed with IRR. The paint layers' structural and compositional aspects were studied non-invasively with XRR, IRR and MA-XRF. The paint/ ground layer sequence and the separate chemical composition of the different strata were further characterized through analysis and study of three cross-sectioned samples by means of OM and FE-SEM-EDX.

\section{Infrared reflectography (IRR)}

Infrared reflectograms were acquired with a commercial OSIRIS infrared camera, manufactured by Opus Instruments (Cambridge, United Kingdom). The OSIRIS was 
equipped with an InGaAs array sensor operating at wavelengths from 900 to $1700 \mathrm{~nm}$, and object resolution down to $0.05 \mathrm{~mm}$ [13]. The painting was recorded with a camera-object distance of $133 \mathrm{~cm}$, a focal length of $28 \mathrm{~mm}$, an $f / 22$ diaphragm and illuminated with two $300 \mathrm{~W}$ Halogen lamps. The entire picture surface was imaged in six recordings of $4096 \times 4096$ pixels each. In Adobe Photoshop CS5 $5^{\circledR}$, the recorded images were finally stitched with Photomerge and the resulting image's legibility was enhanced by histogram correction and the application of the filter Unsharp Mask.

\section{$\mathrm{X}$-ray radiography (XRR)}

Radiographic images were produced at the Royal Institute for Cultural Heritage (KIK/IRPA, Brussels). An air-cooled X-ray tube Baltospot LLX110-DA-1 (Balteau NDT, Hermalle-sous-argenteau, Belgium) was placed in front of the painting and the transmitted X-rays were collected on X-ray polyester films (Agfa Structurix D4). For this painting, a tube voltage of $50 \mathrm{kV}$, a tube current of $12 \mathrm{~mA}$, an exposure time of $480 \mathrm{~s}$, and a distance between source and X-ray films of $6 \mathrm{~m}$ were used.

\section{Macro X-ray fluorescence scanning (MA-XRF)}

The MA-XRF scanning instrument consisted of an X-Beam Powerflux X-ray tube (XOS, New York, USA) with Mo-anode and a Vortex EX- 90 SDD detector (Hitachi High-Technologies Corpon, Chiyoda, Tokyo, Japan), which was placed in a $45^{\circ}$ geometry. The emitted X-rays were collimated employing a dedicated polycapillary lens with a $50 \mu \mathrm{m}$ focal spot. The scanner head was mounted on a linear XY-motorized stage (ILS-LM Series Newport Corporation, Irvine, USA) with a maximum travel range of $570 \times 600 \mathrm{~mm}$ enabling controlled and accurate movement of the apparatus along the paint surface. The painting was mounted vertically on a wooden easel and the motorized stage of the MA-XRF scanner was placed parallel to the picture surface. The whole scanning process was executed in air at a voltage of $45 \mathrm{kV}$ with a current of $200 \mu \mathrm{A}$, a dwell time of $200 \mathrm{~ms}$ and a step size $850 \mu \mathrm{m}$. The entire picture plan was scanned in six experiments, each scanned area measuring $56 \times 51 \mathrm{~cm}$ and each scan taking $24 \mathrm{~h}$. The elemental distribution maps were obtained by using in-house written Datamuncher software of the AXES group (University of Antwerp) [14].

\section{Optical microscopy (OM) and field emission scanning electron microscopy coupled with energy dispersive X-ray spectroscopy (FE-SEM-EDX)}

For the study of the paint stratigraphy, composition and morphology of the ground layer(s), samples smaller than $1 \mathrm{~mm}^{2}$ were extracted with a medical scalpel from areas already damaged and loosened. In total, three samples were obtained from Saint Jerome's left foot, red drapery and the blue sky (locations S1, S2 and S3 are shown in Fig. 1a). The samples were embedded in Technovit ${ }^{\circledR} 2000$ LC, a fast light-curing methacrylate based resin, and hardened by UV-light in the Technotray CU light curing device (Heraeus Kulzer GmbH, Wehrheim, Germany). The polymerized block of synthetic resin was mechanically polished with the Buehler Phoenix Alfa ${ }^{\circledR}$ grinder equipped with a Vector power head (Buehler, Illinois, USA). First, the cross-sectioned samples were documented with the optical microscope Olympus BX 41 (Olympus America Inc., New York, USA). Second, the morphology of the paint crosssections was studied with FE-SEM-EDX Quanta 250 $\left(\mathrm{FEI}^{\mathrm{TM}}\right.$, Oregon, USA) equipped with an Oxford EDAX detector at the research group Electron Microscopy for Materials Science (EMAT, University of Antwerp). The secondary electron (SE) images were collected in low vacuum mode at $200 \mathrm{~Pa}$, and X-ray spectra and maps were obtained in low vacuum, at an accelerating voltage of $15 \mathrm{kV}$ and measuring spot of 4,5. The FE-SEM-EDX results were summarized in Table 1, with the sample location, descriptions of the layer type, and a tentative list of fillers and pigments.

\section{Table 1 List of elements identified with FE-SEM-EDX in the different layers}

\begin{tabular}{|c|c|c|c|c|}
\hline Sample & Layers & & Elements detected & Pigments and fillers implied \\
\hline S1-S3 & Ground & & $\mathrm{Ca}, \mathrm{Fe}, \mathrm{Al}, \mathrm{Si}, \mathrm{Pb}, \mathrm{K}, \mathrm{Hg}$ & Calcite, iron- and silica-rich red earths, lead white and vermilion \\
\hline S1-S3 & Priming & & $\mathrm{Pb}, \mathrm{Ca}$ & Lead white and calcite \\
\hline \multirow[t]{3}{*}{ S2 } & Red cloak & L1 & $\mathrm{Ca}, \mathrm{Fe}, \mathrm{Al}, \mathrm{Si}, \mathrm{Pb}, \mathrm{K}$ & Calcite, iron- and silica-rich red earths and lead white \\
\hline & & $\mathrm{L} 2$ & $\mathrm{Ca}, \mathrm{Fe}, \mathrm{Al}, \mathrm{Si}, \mathrm{Pb}, \mathrm{K}, \mathrm{Hg}$ & Calcite, iron- and silica-rich red eaths, lead white and vermilion \\
\hline & & L3 & $\mathrm{Ca}, \mathrm{Fe}, \mathrm{Al}, \mathrm{Si}, \mathrm{P}, \mathrm{S}, \mathrm{K}$ & Red lake and iron- and silica-rich red earths \\
\hline S3 & Blue sky & & $\mathrm{Ca}, \mathrm{K}, \mathrm{Fe}, \mathrm{Co}, \mathrm{Ni}, \mathrm{As}, \mathrm{Al}, \mathrm{Si}, \mathrm{Pb}$ & Calcite, lead white and smalt \\
\hline S1 & Flesh tones (shadow) & & $\mathrm{Ca}, \mathrm{K}, \mathrm{Mn}, \mathrm{Fe}, \mathrm{Al}, \mathrm{Si}, \mathrm{Pb}, \mathrm{K}, \mathrm{Hg}$ & $\begin{array}{l}\text { Calcite, lead white, iron- and silica-rich red earths, } \\
\text { manganese-based brown earths and vermilion }\end{array}$ \\
\hline
\end{tabular}




\section{Results and discussion}

\section{Literature review: the young Van Dyck's fingerprint}

As mentioned in the introduction, from a stylistic point of view, Van Dyck's oeuvre is both chronologically and geographically divided into four periods (see Fig. 1). From a technical perspective, this division must be considered since the materials and techniques used during these four periods depended on whatever raw materials were available in the different artistic centers [15-17].

In total, technical information was found on 33 canvas paintings in 16 publications [15-30]. Works on panel and paper were not taken into account as the buildup is expected to deviate substantially from works on canvas. Figure 2 indicates how these reference paintings are distributed over the four periods. However, solely the first Antwerp Period will be discussed here because the artist was only preoccupied with this iconographic theme during this phase of his career. As the graph demonstrates, 12 reference works can be situated in the First Antwerp Period, which is $16 \%$ of his known production on canvas of that time. ${ }^{1}$ Although this sample leaves room for uncertainty, the relative consistency within the data of this period suggests that this corpus is representative. In Table 2, an overview of the findings on Van Dyck's materials and techniques for the First Antwerp Period is given.

\section{Comparative study: the young Van Dyck's fingerprint versus the disputed painting Support}

During the First Antwerp Period, Van Dyck mainly painted on canvas to realize large-scale works like the Saint Jerome paintings. More precisely, of the 132 surviving paintings by the young master, 75 works are on canvas (see footnote 1). This fabric support apparently fitted the young master's rough and economic painting technique [17]. Furthermore, literature suggests that Van Dyck preferred dense, plain-weave linen during his formative years in Antwerp. The original support of the painting under study is also a (single piece) plain-weave canvas. OM observations of a single thread removed from the canvas revealed transverse dislocations and markings (nodes), characteristic for flax fibers (Fig. 3) [31]. However, the weave density is low (10 horizontal warp threads and 10-11 vertically running weft threads/cm) while Van Dyck employed much denser linen with an average thread count of 15 horizontal warp and 14 vertical weft threads/ $\mathrm{cm}^{2}$ Also in the cases when the young artist used the herringbone twill-weave linen (3 from 12 reference works), the weave count is higher. In sum, the medium-quality

\footnotetext{
${ }^{1}$ The number of paintings was defined on the basis of Barnes et al. [10], oil sketches on canvas, panel or paper were not included here.

2 The average thread count is determined on the basis of Alba et al. [30]; Fryklund and Lammertse [29] and Roy [16].
}

canvas of the disputed painting, with threads of different thickness, seems to deviate from the higher-quality textile that characterizes the young Van Dyck's painting practice.

\section{Ground layers}

According to publications, during his early years in Antwerp, Van Dyck painted on white and grey-colored chalk grounds, either single or double layered. The matrix of these layers was chalk with addition of some lead white while the grey color was obtained by intermixing small amounts of red lead and/or brown to red earths, next to carbon-based black. In case of a double-layered preparation (8 paintings out of 12 ), a grey priming was thinly applied on top of a thicker white or grey ground. For all these 8 reference paintings, the priming mixtures displayed a slight variation in tonality depending on the ratio of lead white, carbon black, brown earths and/or chalk [30]. However, during his stay in Italy (1621-1627) and upon his return to Flanders (1627-1632), he adopted the Italian and new Netherlandish customs of strongly colored grounds. From then onwards, next to white and grey-colored chalk grounds, he worked on single brown-colored grounds or double red grounds with grey priming [16-23, 28]. Yet, Van Dyck kept using the same pigment mixture for his grey primings as during the First Antwerp Period.

The canvas preparation of the Saint Jerome painting displays such a double red ground with grey priming, as illustrated by Fig. 4a. Correlating the chemical elements detected by means of SEM-EDX analysis $(\mathrm{Ca}, \mathrm{Pb}$, $\mathrm{Al}, \mathrm{Si}, \mathrm{Fe}$ and $\mathrm{Hg}$ ) with the visual information obtained through the OM, shows that this red ground is composed of calcite $\left(\mathrm{CaCO}_{3}\right)$ mixed with a fair amount of iron- and silica-rich earths (iron oxide reds, quartz and clay) and tiny quantities of vermilion and lead white (Fig. 4c, d). Furthermore, the EDX spectra indicated that the grey priming comprises lead white and calcite (Fig. 4e), and acquired its light grey color from the addition of charcoal black. The distinct morphological structure of the latter, i.e. the tangential surface's multiseriate ray parenchyma cells, was observed under the OM as illustrated by Fig. 4b [32]. In short, the double red ground with grey priming found in the Saint Jerome painting corresponds to Van Dyck's later practice (1621-1641) and is not reconcilable with the stylistic attribution of this work to Van Dyck's earliest period.

\section{Underdrawing}

Van Dyck applied the underdrawing in two phases. With a carbon-based dry medium, he first drew freehand the outlines of the figures, the principal lines and hatched shadows of the drapery, and the composition of the background [30]. Details such as the figures' physiognomy were not delineated in his underdrawings. This phase is 


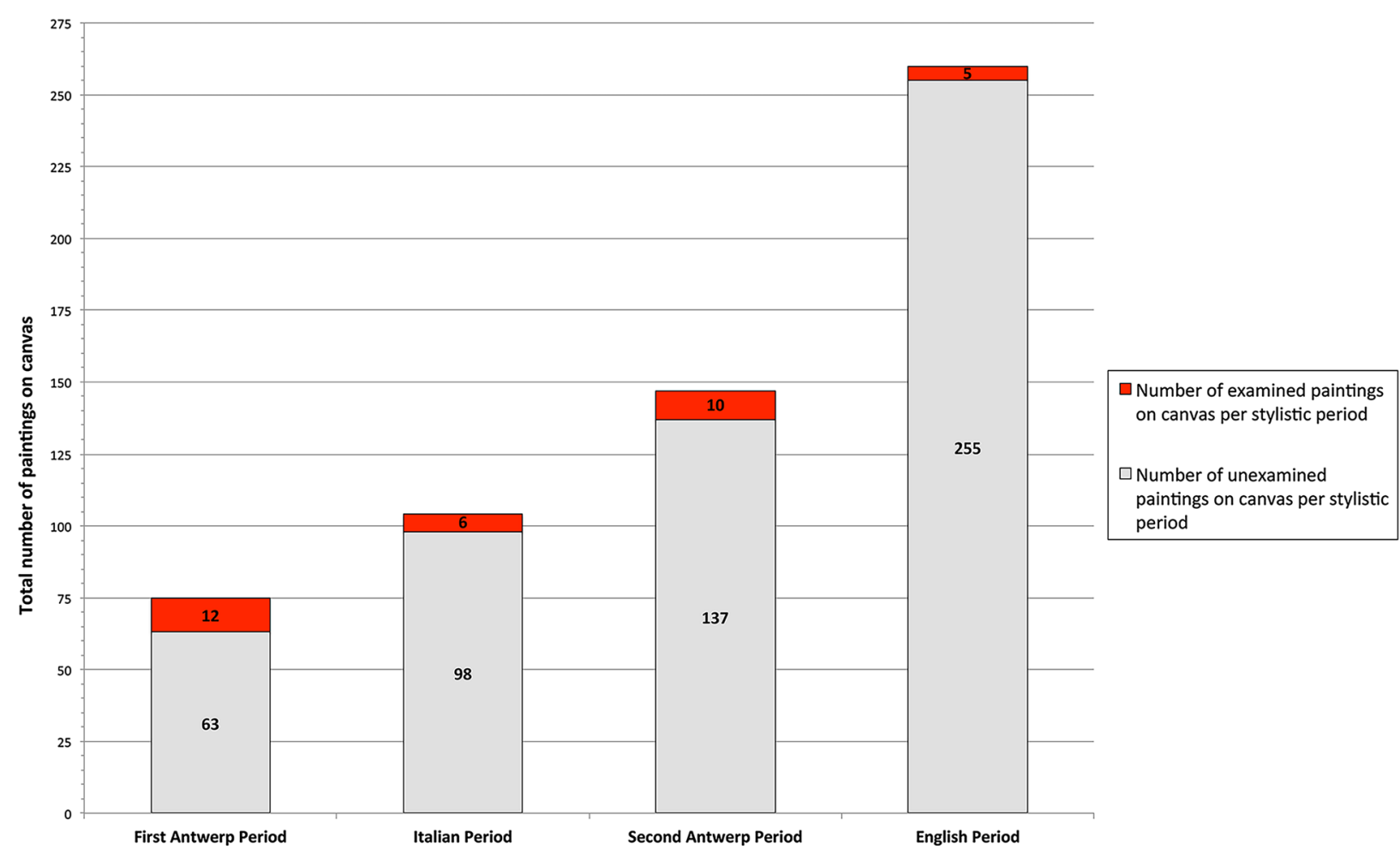

Fig. 2 Graph showing the distribution of the examined reference paintings on canvas over the four periods

in principle visible with IRR. Second, these fine outlines and hatched shadows were reinforced and reworked with a brush and translucent red brownish paint [29]. This is not visible in IRR. Literature indicated that the paint mixture employed by Van Dyck includes manganese and iron-containing pigments, i.e. umber or Cassel earth, and a little carbon-based black, especially for the shadow areas $[17,18]$. Nevertheless, in some cases (6 of paintings out of 12) infrared research did not reveal traces of an initial dry medium sketch. Therefore, it is possible that Van Dyck also used a more direct approach by roughly sketching out the design on canvas with a brush and the aforementioned fluid paint [29,33].

Similar to the young Van Dyck's practice, a twofold drawing method was adopted in the disputed painting. IRR showed some traces of simple freehand drawing applied on top of the grey priming with a dark, infrared absorbing dry medium (charcoal or black chalk) (see Fig. 5c). ${ }^{3}$ Next to that, examination of the painting surface also revealed dark brown outlines freely applied with a brush and a liquid medium. These dark brushstrokes

\footnotetext{
${ }^{3}$ Caution must be exercised in interpreting the infrared reflectogram. Specifically, the effectiveness of infrared reflectography decreases due to (1) the usage of light colored grounds, which are less reflective than white chalkbased preparation layers (2) the application of thick paint layers and (3) the use of low infrared-absorbing drawing materials.
}

were clearly observable at the painting surface in an area where compositional change was introduced, i.e. the repositioned outlines of Saint Jerome's left hand shown in Fig. 5e. The exact nature of the employed dark brown fluid medium could not be determined because these brushstrokes did not show up in any of the MA-XRF maps. Hence, this finding excluded the presence of traditional iron and manganese-based brown pigments such as umber, Cassel earth or brown ochre (Fig. 6a, c). However, The $\mathrm{K}$ distribution map revealed the presence of potassium, a possible trace element of red lake substrates [34], in areas where the painted sketch was present (see Fig. 6b). Consequently, a paint mixture containing pigments that cannot be detected by means of MA-XRF scanning was suspected, e.g. red lake and a carbon black pigment (Fig. 5d, e). Further analysis of (cross-sectioned) samples would be needed to pinpoint the exact nature of the fluid medium. In summary, while the painting's twofold underdrawing technique matched Van Dyck's art practice, the material used for the brushed sketch did not accord with the young master's typical use of a dark, translucent brown iron and manganese-rich pigment.

\section{Paint layers}

Literature on young Van Dyck's studio practice indicated that the artist's paint materials were in line with 
Table 2 Overview of the young Van Dyck's technical fingerprint

\begin{tabular}{|c|c|c|c|c|c|c|c|c|c|c|c|c|c|c|}
\hline & & & & Ref & eren & ce paint & ings - & First & Antw & $\mathrm{rpPe}$ & $\operatorname{iod}($ & 1613-'2 & & \\
\hline & & & 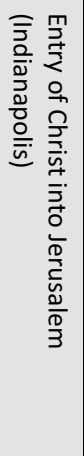 & 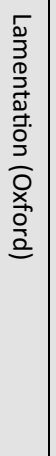 & 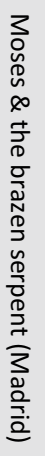 & 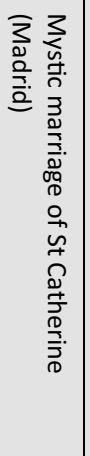 & 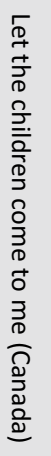 & 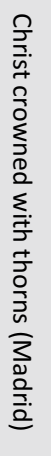 & 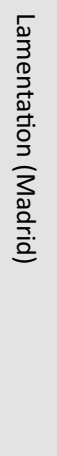 & 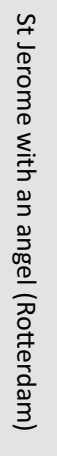 & 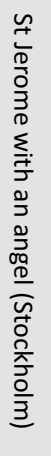 & 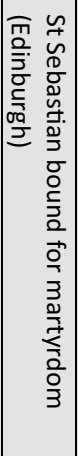 & 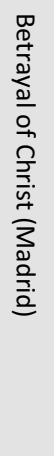 & 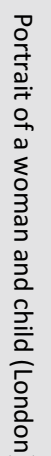 \\
\hline$\frac{t}{2}$ & $\begin{array}{l}\text { Dense } \mathrm{pl} \\
\text { threads/ }\end{array}$ & $\begin{array}{l}\text { in-weave canvas ( } \geq 12 \\
\mathrm{~m} \text { ) }\end{array}$ & & & & & & & & & & & & \\
\hline ڤั山 & Herringb & ne twill-weave canvas & & & & & & & & & & & & \\
\hline & Single & Grey chalk ground & & & & & & & & & & & & \\
\hline 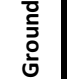 & Double & $\begin{array}{l}\text { White chalk ground + grey } \\
\text { priming }\end{array}$ & & & & & & & & & & & & \\
\hline & & Grey chalk ground + grey priming & & & & & & & & & & & & \\
\hline & Sketch a & plied with brush in fluid medium & & & & & & & & & & & & \\
\hline 竧 & $\begin{array}{l}\text { Dry med } \\
\text { in a fluid }\end{array}$ & $\begin{array}{l}\text { um drawing reinforced with brush } \\
\text { nedium }\end{array}$ & & & & & & & & & & & & \\
\hline & Not iden & ified & & & & & & & & & & & & \\
\hline & Indigo & & & & & & & & & & & & & \\
\hline I & Indigo + & zurite glazing & & & & & & & & & & & & \\
\hline 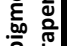 & Indigo $\mathrm{m}$ & xed with azurite & & & & & & & & & & & & \\
\hline$\frac{0}{2}$ & Not iden & fied & & & & & & & & & & & & \\
\hline & Not appl & cable & & & & & & & & & & & & \\
\hline$\frac{2}{2}$ & Azurite & & & & & & & & & & & & & \\
\hline 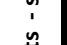 & Indigo & & & & & & & & & & & & & \\
\hline$\stackrel{\Xi}{\Xi}$ & Smalt & & & & & & & & & & & & & \\
\hline$\frac{00}{0}$ & Not iden & fied & & & & & & & & & & & & \\
\hline$\frac{1}{\infty}$ & Not appl & cable & & & & & & & & & & & & \\
\hline$\geq$ & Vermilio & + red lake glazing & & & & & & & & & & & & \\
\hline 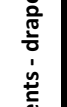 & $\begin{array}{l}\text { Vermilio } \\
\text { based fill } \\
\text { lake and }\end{array}$ & $\begin{array}{l}\text { mixed with red lake and calcium- } \\
\text { rs or red earths }+ \text { glazing of red } \\
\text { ermilion }\end{array}$ & & & & & & & & & & & & \\
\hline$\sum_{\frac{.0}{2}}^{\frac{.0}{2}}$ & $\begin{array}{l}\text { Vermilio } \\
\text { carbon b }\end{array}$ & $\begin{array}{l}\text { mixed with iron red, lead white or } \\
\text { ack }+ \text { red lake glazing }\end{array}$ & & & & & & & & & & & & \\
\hline ๘ँ & Not iden & fied & & & & & & & & & & & & \\
\hline 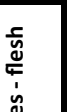 & $\begin{array}{l}\text { Male } \\
\text { figures }\end{array}$ & $\begin{array}{l}\text { Vermilion mixed with lead white, } \\
\text { carbon black, calcite, gypsum, } \\
\text { brown and/or red earths }\end{array}$ & & & & & & & & & & & & \\
\hline 岂 & & Not identified & & & & & & & & & & & & \\
\hline 它 & $\begin{array}{l}\text { Female } \\
\&\end{array}$ & $\begin{array}{l}\text { Lead white with some vermilion } \\
\text { and red earths }\end{array}$ & & & & & & & & & & & & \\
\hline$\frac{L_{0}}{20}$ & $\begin{array}{l}\text { infant } \\
\text { figures }\end{array}$ & Not identified & & & & & & & & & & & & \\
\hline
\end{tabular}




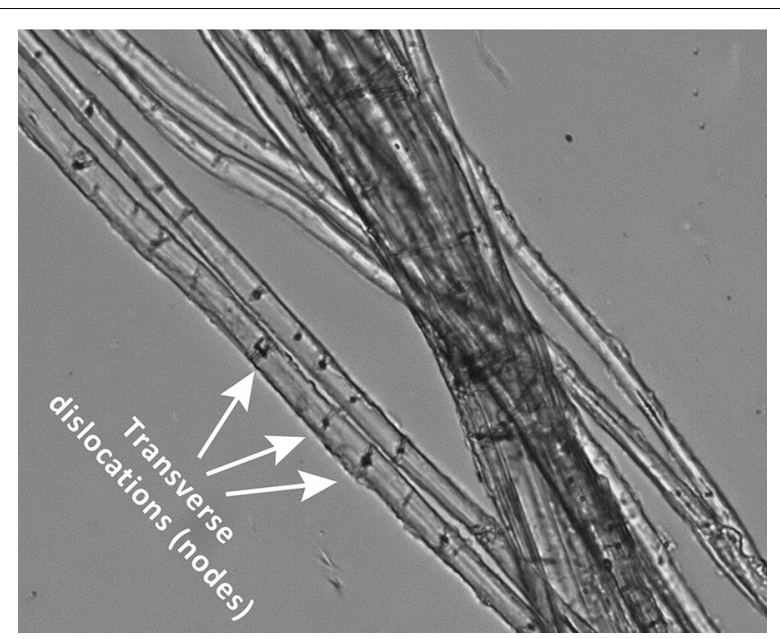

Fig. 3 Sample from the canvas support: flax fibers under light microscope in reflective mode ( $D F, \times 20)$, annotated to indicate the characteristic transverse dislocation and markings of flax

what one would expect to find in early seventeenth-century canvas painting [17]. Van Dyck's color palette contained the traditional (1) natural mineral pigments, i.e. azurite and earth pigments; (2) synthetic pigments vermilion, i.e. smalt, copper-based greens, lead-tin yellow, lead white and carbon blacks; and (3) manufactured organic dyestuffs such as indigo and red lake. The total absence of the expensive blue pigment ultramarine in the young master's color palette as well as his extensive usage of the unstable blue dyestuff indigo was remarkable for that time and perhaps idiosyncratic [30]. The range of materials was thus confined. Cross-sections of the reference paintings showed that more than three layers of paint were uncommon, and complex layering was limited to areas with compositional changes. To extend the chromatic range, Van Dyck relied on pigment mixtures. Bright pigments were not used at full strength but were mixed with pigments such as lead white, calcite, gypsum, earths and carbon blacks. Particularly relevant for this study is the fact that, in Van Dyck's early paintings, there was a clear distinction between the paint stratigraphy of clothing, skies and human flesh.

For the depiction of draperies and skies, the master obtained subtle color designs by employing a stratified system with underlying layers that were allowed to dry before subsequent layers were applied. In particular for the draperies, passages of translucent glazes were superimposed on strongly pigmented underpainting in order to temper the color tone of the latter and/or to modulate forms and deep shadows. In the case of dark red and blue colored draperies, loose impastos of bright paint were added to evoke the highlights. For instance, the underpainting of red draperies was composed of vermilion mixed with lead white, sometimes with small addition of iron reds, red lakes and/or calcium-based fillers (calcite and gypsum) to further modify the vivid color of vermilion. Next, transparent glazes were employed in areas of shadow, based on red lake with the addition of a carbon-based black. Finally, impastoed highlights containing vermilion mixed with lead white and red lake were applied.

The red drapery of Saint Jerome exhibits a threefold structure and composition that is quite similar to Van Dyck's formulaic technique of paint application. OM observations of the paint cross-section (S2 in Fig. 7a), removed from a dark fold of the red cloak (Fig. 1a), revealed (L1) a thinly applied reddish underpaint consisting of calcite mixed with iron oxide reds and lead white, (L2) a second, slightly thicker, red paint layer containing vermilion, calcite with small amounts of iron oxide reds and lead white, covered with (L3) a faded layer of glazing likely composed of a red lake mixed with iron reds. ${ }^{4}$ Restricted by the used analytical methods, the exact composition of this top glazing has not been identified. However, the EDX spectrum (Fig. 7b) collected in the top glaze was dominated by calcium, aluminum and sulfur peaks along with small peaks for phosphorus and potassium. This suggests the usage of a lake with a potassium alumina substrate and/or calcium and sulfate [34]. Furthermore, major peaks for iron and silicon were also visible in the EDX spectrum, indicating the presence of iron reds in this top layer. In addition, based on the distribution of the infrared-absorbing carbon black pigment observable in the IRR, we could deduce that the paint used for the red fabric's dark folds and shadows also comprise carbon black (see Fig. 5a). As such, the folds and deep shadows of the Saint's red garment gained their final form.

Visual examination established that the bright areas of the red fabric were painted out with a strongly pigmented red paint, which was clearly not tempered. The $\mathrm{Hg}$ distribution map (Fig. 6d) indicated the dominant presence and distribution of the red pigment vermilion in these bright red zones. Perhaps this vermilion-based paint was thickly applied on top of the more faintly red-colored layers of underpainting, present in the cross-sectioned sample S2. Highlights were indicated in this way, which were further strengthened in some areas (e.g. located at the Saint's left

\footnotetext{
4 The microscopic study of the cross-section revealed a photochemical degraded upper layer of red glaze along with formation of whitish surface crusts. EDX analysis of this region demonstrated the presence of $\mathrm{Ca}, \mathrm{Al}$, $\mathrm{S}, \mathrm{Si}, \mathrm{P}$ and $\mathrm{K}$. Most likely, these surface deposits derive from a chemical reaction between the salt mixtures rich in potassium and sulphur and atmospheric compounds. Further analysis of the cross-sectioned sample is considered desirable to study the cause and nature of the degradation process.
} 


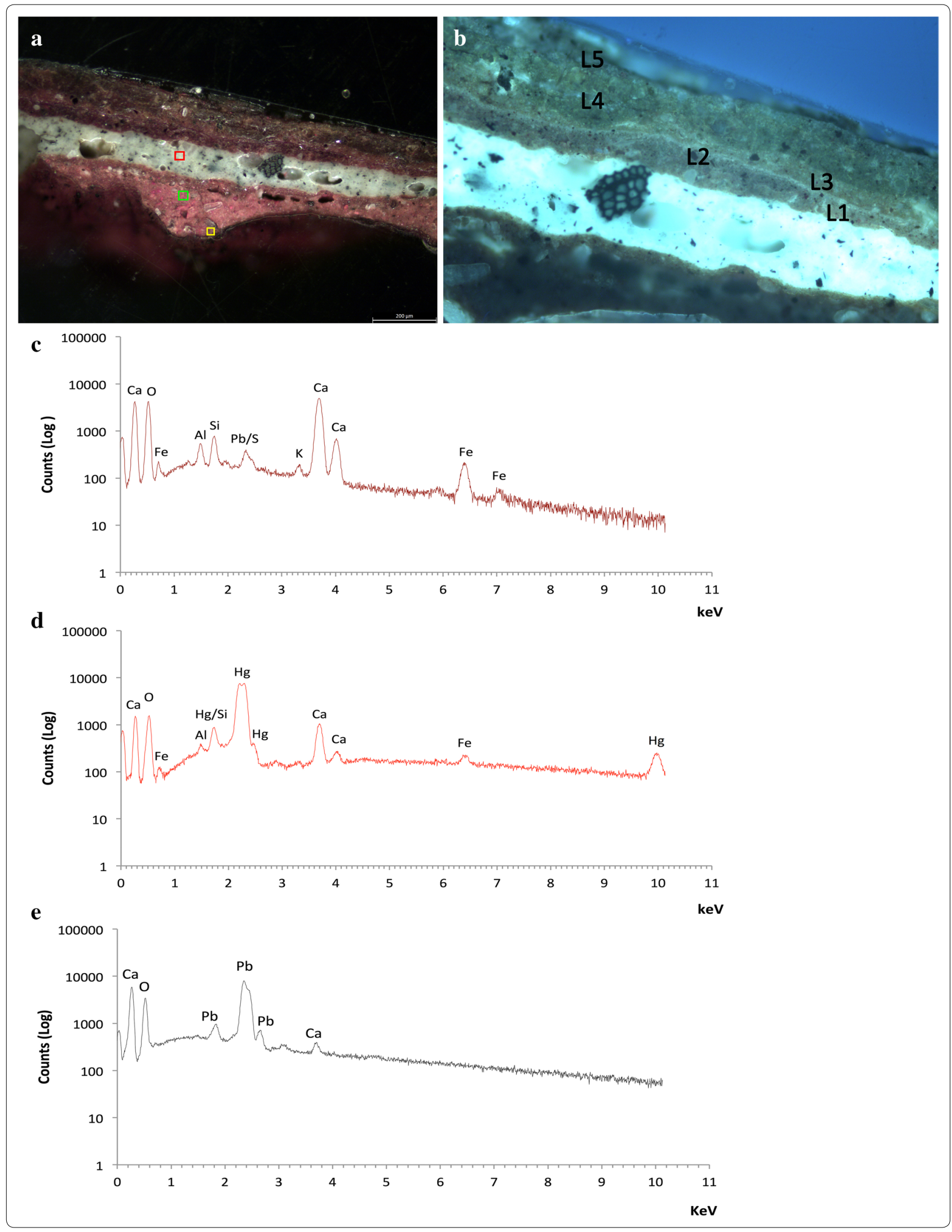




\section{(See figure on previous page.)}

Fig. 4 Flesh tone sample S1 from Saint Jerome's left foot: a cross-section under light microscope $(D F, \times 10)$; b microscopic image $(U V$, $\times 20)$, labeled with L1-L5 to indicate the five-layered stratigraphy, showing a fragment of charcoal and the wet-into-wet application of the carnation colors; $\mathbf{c}$ EDX spectrum indicating the presence of $\mathrm{Ca}$, $\mathrm{Al}$, Si and Fe in the red ground, measuring position is indicated by a yellow box in (a); $\mathbf{d}$ EDX spectrum indicating the presence of $\mathrm{HgS}$ in the red ground, measuring position is indicated by a green box in (a); e EDX spectrum showing the presence of Pb and $\mathrm{Ca}$ in the grey priming, measuring position is indicated by a red box in (a)

knee) by adding a successive layer composed of lead white and vermilion. This finding was confirmed by the composite X-ray image showing constructive brushwork in the brightest parts of the red fabric (see Fig. 5b).
Previous authors reported that Van Dyck practiced a similar layering and mixing method for obtaining various blue color tones to paint out draperies and skies, depending on three different blue pigments: indigo, smalt and
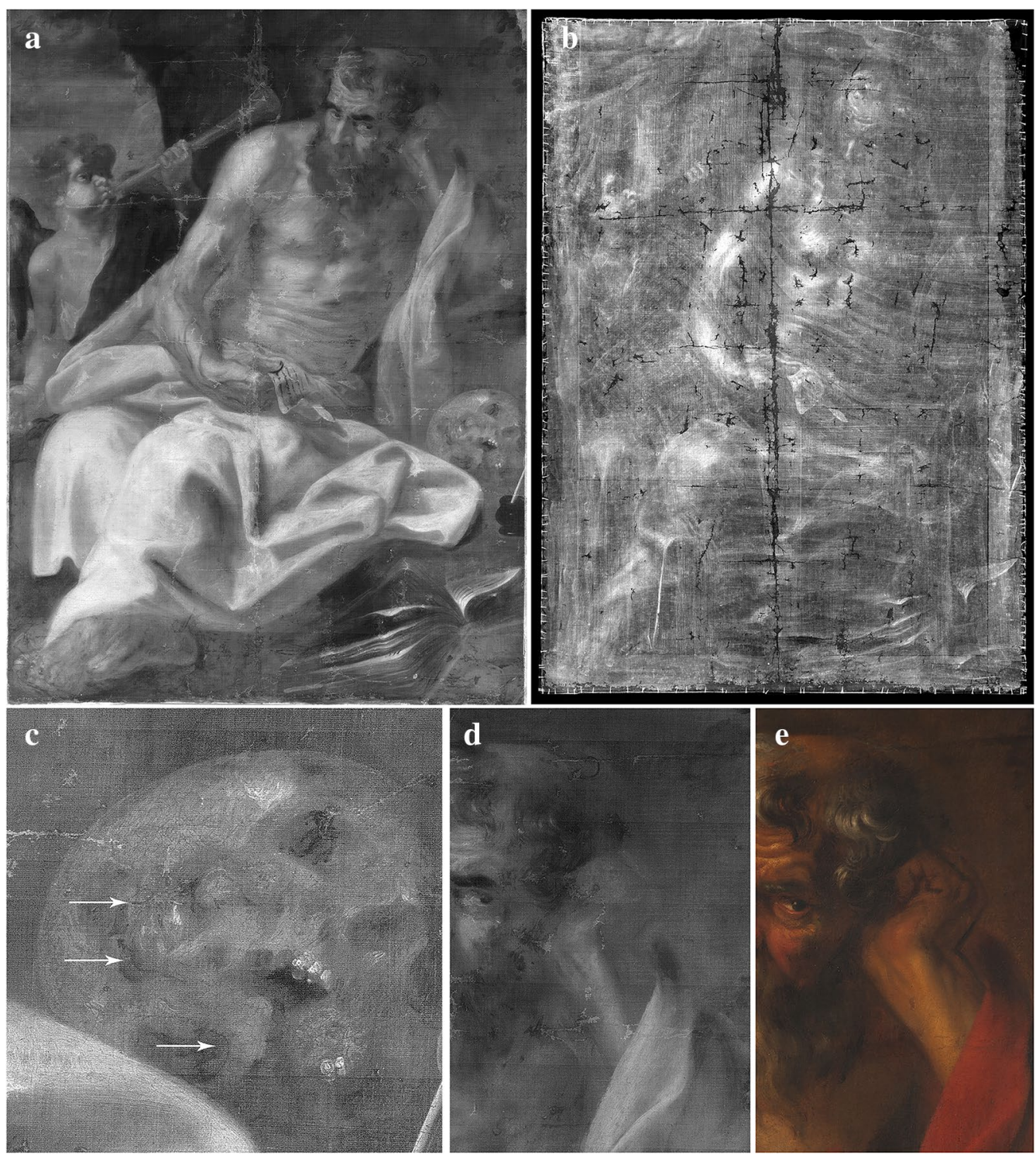

Fig. 5 a Infrared reflectogram; b composite X-ray image; c annotated IRR detail of the skull showing drawing lines applied with a carbon-based dry medium; $\mathbf{d}$ IRR detail of St Jerome's left hand showing traces of the carbon-based fluid medium along with $\mathbf{e}$ visible wavelength close-up image of the same area showing the reworked dark outlines applied with a brush and fluid medium 


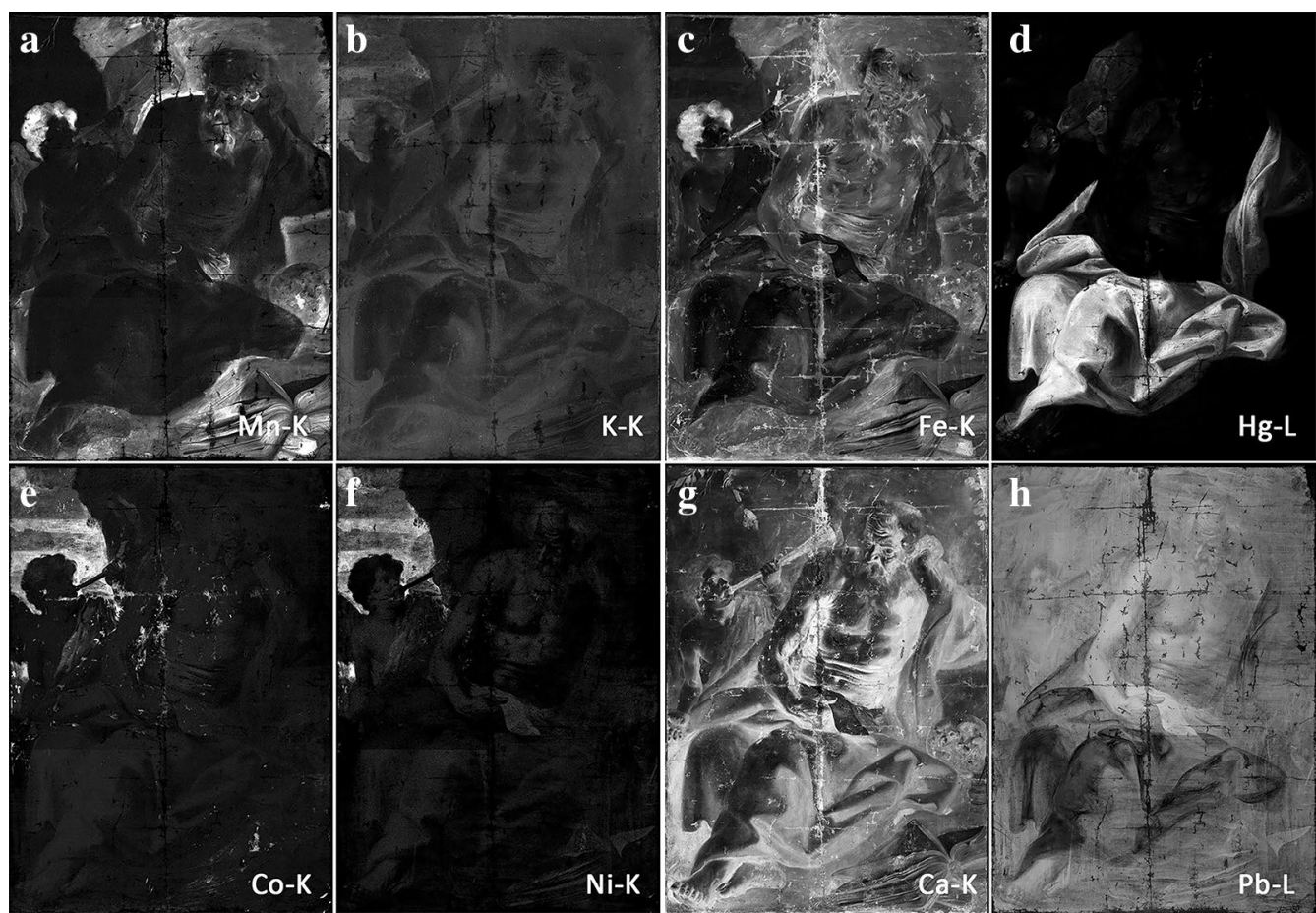

Fig. 6 Elemental maps of the whole painting obtained with MA-XRF: a Mn; b K; c Fe; $\mathbf{d ~ H g ; ~ e ~ C o ; ~ f ~} \mathrm{Ni} ; \mathbf{g} \mathrm{Ca} ; \mathbf{h} \mathrm{Pb}$

azurite [29, 30]. For the draperies, Van Dyck achieved a chromatic range from light to dark blue by mixing small amounts of lead white to indigo, his preferred blue pigment for realizing draperies. Lead white was added either alone $^{5}$ or in combination with carbon black ${ }^{6}$ or with brown and red earths. ${ }^{7}$ More green-bluish color tones were obtained by blending or glazing indigo with azurite. Interestingly, the young artist also created optical dark grey-blue areas without the use of an actual blue pigment, i.e. by mixing charcoal black, red lake and lead white. However, none of these combinations, characteristic for the young Van Dyck's working methods, were found in the blue drapery of the disputed painting. The $\mathrm{Co}, \mathrm{Ni}$ and $\mathrm{K}$ distribution maps established the presence of the blue pigment smalt in the blue drapery (Fig. $6 \mathrm{~b}$,

\footnotetext{
5 This pigment mixture is used in the paintings: (1) Anthony van Dyck, Christ crowned with thorns, 1618-1620, oil on canvas, $225 \times 197 \mathrm{~cm}$, Museo Nacional del Prado, Madrid, (2) Anthony van Dyck, Saint Sebastian bound for Martyrdom, 1620-1621, oil on canvas, $223 \times 160 \mathrm{~cm}$, Scottish National Gallery, Edinburgh.

6 This pigment mixture is used in the works: (1) Anthony van Dyck, The Lamentation, 1617-1618, oil on canvas, $207 \times 137 \mathrm{~cm}$, Ashmoleum Museum, Oxford, (2) Anthony van Dyck, The Lamentation, 1618-1620, oil on canvas, $203 \times 170 \mathrm{~cm}$, Museo Nacional del Prado, Madrid.

7 This paint mixture is employed in the blue drapery of the Virgin of the painting: Anthony van Dyck, The Mystic Marriage of St Catherine, 16181620 , oil on canvas, $124 \times 174 \mathrm{~cm}$, Museo Nacional del Prado, Madrid.
}

e-f). ${ }^{8}$ The Co map indicated that smalt was only present in the mid-tones and lights of the painted drapery and was not or hardly applied in the shadow areas. Visual examination, established that the paint of the blue drapery was made up of up to two layers and was applied sparingly, leaving the ground locally exposed. No opaque underpainting was applied to define the general form and undertone of the blue drapery. The deep shadows of the blue fabric were blocked in first using carbon black. The latter is not detectable by MA-XRF imaging, but IRR visualized the distribution of this infrared-absorbing carbon black pigment in the angel's blue tunic (see Fig. 5a). Next, the mid-tones were modeled by applying thin passages of glazes composed of smalt mixed with calcite and small amounts of carbon black. Afterwards, this dark blue paint layer was subtly lightened with lead white mixed with smalt in the highlights.

There were no discrepancies identified with the young Van Dyck's materials and techniques for the structure and composition of the sky. A cross-section (S3 in Fig. 1a)

\footnotetext{
${ }^{8}$ It is remarkable that in the blue areas of the painting, i.e. both the blue drapery as well as the sky, no traces of the chemical element arsenic (As) were found through MA-XRF scanning. Nonetheless, small amounts of As were traced in the cross-sectioned sample $\mathrm{S} 3$ of the blue sky by means of SEM-EDX analysis. Hence, it remains unclear if this discrepancy is due to the fact that the smalt-containing paint layers are very thinly applied or whether it is associated with technical limitations of the MA-XRF scanning.
} 

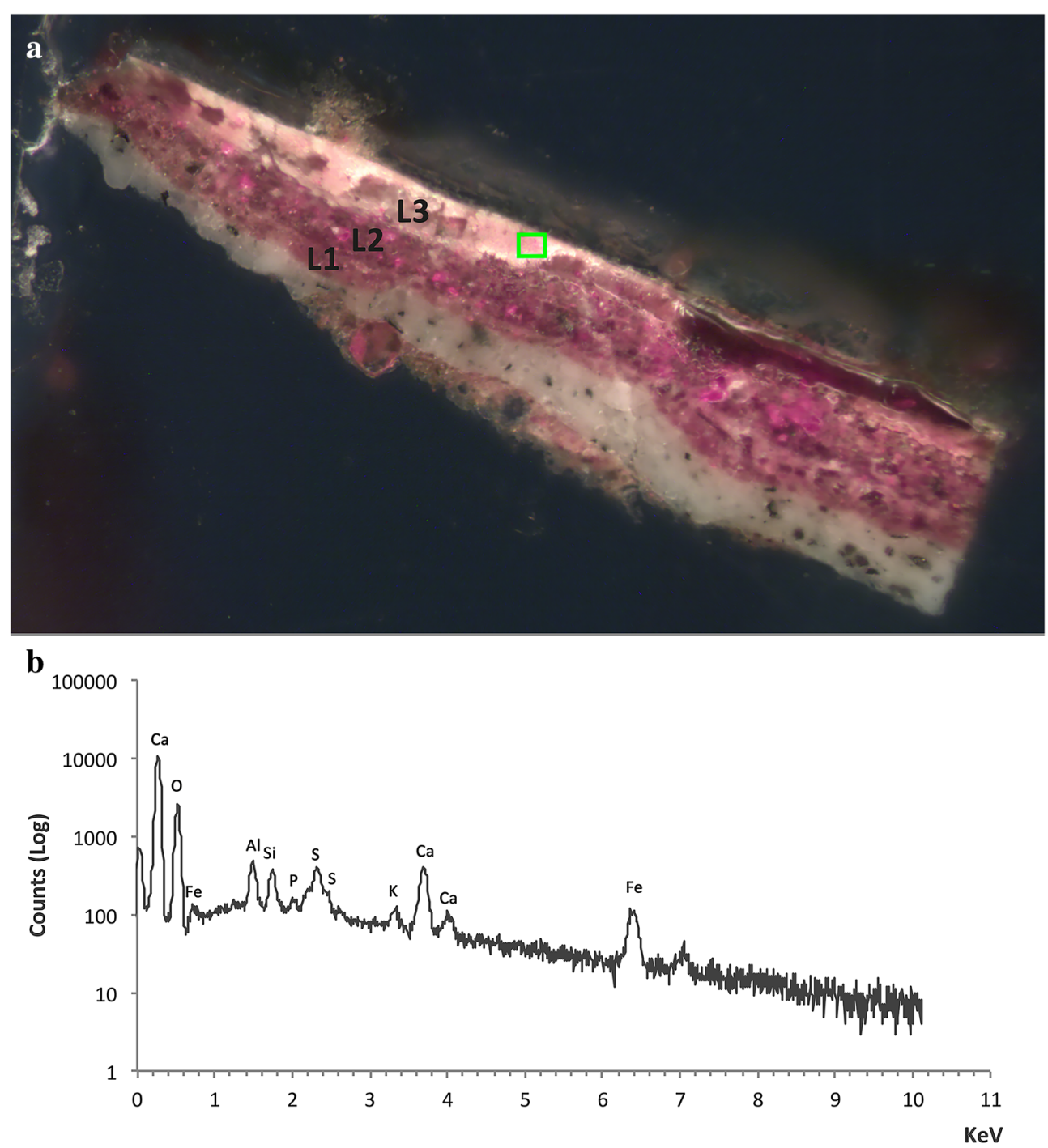

Fig. 7 Red drapery sample S2 from a dark fold of the red cloak: a cross-section under light microscope $(D F, \times 20)$ labeled with $L 1-L 3$ to indicate the three-layered stratigraphy; $\mathbf{b}$ EDX spectrum indicating the presence of $\mathrm{Ca}, \mathrm{Al}, \mathrm{S}$ along with $\mathrm{P}$ and $\mathrm{K}$ in the top glazing, the measuring position is indicated by a green box in (a)

taken from a light blue area of the sky revealed that this zone was based on smalt. EDX analysis pinpointed the predominant presence of calcium $(\mathrm{Ca})$, potassium $(\mathrm{K})$, arsenic (As), silicon $(\mathrm{Si})$, and lead $(\mathrm{Pb})$ as well as minor amounts of iron (Fe), cobalt ( $\mathrm{Co})$, nickel $(\mathrm{Ni})$ and aluminum (Al). Hence, in these light blue areas smalt was mixed with large amounts of calcite and lead white. The Co and Ni distribution maps of MA-XRF scanning indicated that the dull grey clouds in the sky contained a considerably lower amount of smalt (Fig. 6e, f), as expected, while, the IRR indicated a higher concentration of carbon black in these darker areas (Fig. 5a). A similar working method of using smalt-based mixtures for the sky area was observed in Van Dyck's early career work, Portrait of Woman and Child (London, National Gallery).

In contrast to the drapery and sky areas, Van Dyck is known to model flesh tones in successive layers while the paint was still wet, resulting in a single but rather thick paint layer [16, 29, 30]. According to previous research, he implemented a different approach for male and women figures. The luminous pinkish tones of female and infant flesh were composed of lead white, lightly tinted with vermilion and red earths in shadow areas. The darker flesh of the male characters was based on vermilion, while lead white, carbon black, calcite, gypsum, brown and/or red earths were added, depending on the required luminosity. 
The $\mathrm{Fe}, \mathrm{Hg}, \mathrm{Ca}$ and $\mathrm{Pb}$ distribution maps of the MA-XRF scanning indicated the presence of similar pigments in the flesh tones of the disputed painting, i.e. calcium, red earths, vermilion and lead white. The element $\mathrm{Ca}$ (Fig. 6g) was mostly present in the shadow areas along with $\mathrm{Fe}$ (Fig. 6c), while the light painted areas are comparable richer in $\mathrm{Hg}$ (Fig. 6d) and $\mathrm{Pb}$ (Fig. 5b). The carnation colors of the angel and Saint Jerome differ in tone, a difference that is reflected in these chemical images as well. The flesh tones of Saint Jerome comprised higher amounts of Fe than the skin of the angel, where the element was only present in the deepest shadows of the face, neck and right $\mathrm{arm}$. The Mn distribution map also indicated that this element is present in the dark shadows of the Saint's skin. The highlights in the Hg map, on the other hand, corresponded to the red paint areas of the angel's skin and only very small areas of the Saint's flesh. Hence, similar to Van Dyck's working method, it seemed that the variation in tonality mainly depended on the ratio of $\mathrm{Pb}, \mathrm{Ca}$, $\mathrm{Hg}$ and $\mathrm{Fe}$ present in the flesh tones. SEM-EDX analysis of a cross-section removed from the Saint's left foot (S1) confirmed the presence of these elements in stratigraphy of the old man's flesh paint.

OM revealed that this area of paint was applied wetinto-wet (see Fig. 4a, b), which indicated that these carnation colors were modeled in successive layers while the paint was still wet. Hence, the sample seemingly comprised about five layers, namely a red layer, a dark redbrown paint, an orange-brown paint layer, dark brown paint and a final orange-brown paint layer (Fig. 4b). These red to dark brown blended paint layers contained mixtures of calcium, lead white, iron- and silica-rich earths and/or manganese-based brown earths and small amounts of organic red lake. The usage of distinct pigment mixtures containing calcite, lead white, carbon black, earths and vermilion in various proportions as well as the wet-into-wet application of the carnation colors thus corresponded to the young Van Dyck's modus operandi.

\section{Conclusion}

The study at hand aimed to re-assess a disputed attribution of the painting Saint Jerome to the young Anthony Van Dyck. In doing so, we adopted a two-fold attribution method that (1) elucidated the young Van Dyck's technical fingerprint based on existing literature and (2) systematically compared the materials and techniques of the disputed painting with said fingerprint. Although there was agreement between the artist's fingerprint and the technical analysis in the areas of the red drapery, flesh and sky, there were more discrepancies, suggesting that the current attribution is incorrect. In summary our findings offered four technical arguments, opposing the attribution to the young Van Dyck: the average quality of the support, the reddish ground layers that are atypical for Van Dyck's early period, the absence of an iron-based earth pigment in the fluid sketching medium and the usage of the blue pigment smalt in the drapery (instead of indigo). Despite the fact that the painting can hardly be attributed to Van Dyck, the technical research does not exclude a seventeenth-century origin because the painting's materials and methods do not depart in any significant way from the standard practice of that period. Apart from enhancing the understanding of the young Van Dyck's studio practice and the disputed painting's materials and techniques, this research demonstrated how the proposed fingerprint method is a suitable object-based instrument for future assessments of questioned attributions, and can complement traditional stylistic analysis.

Although this study unilaterally focuses on the young van Dyck, the developed methodology might be generalizable towards other masters as well. However, a significant limitation of this approach is its dependency upon the presence as well as the quality of previously published studies on Van Dyck's work. Although we believe that the studies used for this research are of high quality, issues regarding our sample representativeness are apparent. We thus await the results of future technical research on early work by Van Dyck to learn whether our method and findings hold as the corpus is supplemented.

\section{Authors' contributions \\ This project was initiated by AH and GB. AH, GVdS, OS, KJ and GB contrib- uted to the acquisition, analysis and interpretation of data. AH and GVdS drafted and revised the manuscript. All authors read and approved the final manuscript.}

\section{Author details \\ ${ }^{1}$ Department of Art, Music and Theatre Sciences, Ghent University - Research Foundation Flanders, St-Pietersnieuwstraat 41 B4, 9000 Ghent, Belgium. ${ }^{2}$ Conservation Studies, Faculty of Design Sciences, University of Antwerp, Blindestraat 9, 2000 Antwerp, Belgium. ${ }^{3}$ Department of Chemistry, AXES Group, University of Antwerp, Groenenborgerlaan 171, 2020 Antwerp, Belgium.}

\section{Acknowledgements \\ The authors are grateful to the staff of the Maagdenhuis Museum Antwerp, especially to Daniel Christiaens and Rudi van Velthoven, for their cooperation and enthusiastic support. Prof. Em. Claudine A. Chavannes-Mazel and Ph.D. student Alice Taatgen (University of Amsterdam) are acknowledged for the IRR recordings. We also would like to acknowledge Dr. Christina Currie (KIK/RPA) and Catherine Fondaire (KIK/RPA) for the XRR, and Eva Grieten (EMAT, Univer- sity of Antwerp) for the FE-SEM-EDX. Finally, the authors wish to thank Prof. Dr. Katlijne van der Stighelen (University of Leuven) and Prof. Dr. Maximilaan Martens (Ghent University) for their art historical insights and additional com- ments. This research was supported by the Baillet Latour fund and Research Foundation Flanders (FWO).}

\section{Competing interests}

The authors declare that they have no competing interests.

\section{Publisher's Note}

Springer Nature remains neutral with regard to jurisdictional claims in published maps and institutional affiliations. 
Received: 14 February 2017 Accepted: 24 April 2017

Published online: 09 June 2017

\section{References}

1. Ainsworth MW. From connoisseurship to technical art history: the evolution of the interdisciplinary study of art. Getty Conserv Inst Newsl. 2005;20:4-10.

2. Hermens E. European paintings 15th-18th century. Copying, replicating and emulating. London: Archetype Publications Ltd; 2014

3. Dijkstra J. Technical Examination. In: Ridderbos B, Van Buren A, Van Veen $H$, editors. Early Netherlandish paintings: rediscovery, reception and research. Amsterdam: University Press; 2005. p. 292-328.

4. Faries M. Reshaping the field: The contribution of technical studies. In: Ainsworth MW, editor. Early netherlandish painting at the crossroads: a critical look at current methodologies. New York: Metropolitan Museum of Art; 2001. p. 70-105.

5. Barry C. Seeing through Renaissance and Baroque Paintings: Case Studies. In: Bohn B, Saslow JM, editors. A companion to Renaissance and Baroque art. Oxford: Wiley-Blackwell; 2013. p. 336-58.

6. Ainsworth MW. What's in a name? The question of attribution in early Netherlandish painting. In: Faries M, Spronk R, editors. Recent developments in the technical examination of early Netherlandish painting. Turnhout: Brepols Publishers; 2003. p. 135-47.

7. Sheldon L, Macaro G. Materials as markers: how useful are distinctive materials as indicators of master or copyist? In: Hermens E, editor. European paintings 15th-18th century. Copying, replicating and emulating. London: Archetype Publications Ltd; 2014. p. 105-12.

8. Christiaens D. Openbaar Centrum voor Maatschappelijk Welzijn van Antwerpen: catalogus museum maagdenhuis. Antwerp: OCMW Antwerpen; 2003. p. 22.

9. Philippen L. Een Jeugdwerk van Antoon van Dyck. In: van Openbare Commissie, Antwerpen Onderstand, editors. Bestuurlijk Verslag over het Dienstjaar 1931. Antwerp: Commissie van Openbare Onderstand; 1933. p. 182-9.

10. Barnes SJ, De Poorter N, Millar O, Vey H. Van Dyck: A complete catalogue of the paintings. New Haven and London: Yale University Press; 2004.

11. Van Glück G. Dyck, des Meisters Gemälde in 571 Abbildungen. Stuttgart: Deutsche Verlags-Anstalt; 1931.

12. Vergara A, Lammertse F, editors. The Young Van Dyck. London: Thames \& Hudson; 2012.

13. Saunders D, Billinge R, Cupitt J, Atkinson N, Liang H. A new camera for high-resolution infrared imaging of works of art. Stud Conserv. 2006;51:277-90.

14. Alfeld A, Janssens K. Strategies for processing mega-pixel X-ray fluorescence hyperspectral data: a case study on a version of Caravaggio's painting Supper at Emmaus. J Anal At Spectrom. 2015:30:777-89.

15. Christensen C, Palmer M, Swicklik M. Van Dyck's painting technique, his writings, and three paintings in the national gallery. In: Wheelock AK, Barnes J, Held JS, editors. Anthony van Dyck 350. Washington D.C: National Gallery of Art; 1994. p. 45-52.

16. Roy A. The National gallery Van Dycks: technique and development. Nat Gallery Tech Bulletin. 1999;20:50-83.
17. Kirby J. The Painter's Trade in the Seventeenth Century: theory and Practice. National Gallery Technical Bull. 1999;20:5-49.

18. Ainsworth MW, Brealey J, Haverkamp-Begemann E, Meyers P. Art and autoradiography: insights into the genesis of paintings by rembrandt, Van Dyck and Vermeer. New York: The Metropolitan Museum of Art; 1987.

19. Woudhuysen-Keller R, Groen K. Sir Anthony van Dyck (1599-1641). The Hamilton Kerr Institute Bulletin. 1988;1:119-20.

20. van Hout N. Meaning and development of the ground layer in seventeenth-century painting. In: Hermens A, editor. Looking Through Paintings. London: Archetype Publications Ltd.; 1998. p. 199-226.

21. Depuydt-Elbaum L, van Dyck A. Antoine van Dyck (1599-1641). Bulletin de l'Institut Royal du Patrimoine Artistique. 1999;28:251-4.

22. Verloo D. La restauration du Golgotha d'Antoine van Dyck à la cathedrale Saint-Rombout de Malines: technique picturale et traitement. Bulletin de I'Institut Royal du Patrimoine Artistique. 2001;29:124-32.

23. Strolz M. Anton van Dyck: Carlo Emanuele d'Este, Marchese di Borgomanero. Jahrbuch der Kunsthistorischen Museum Wien. 2001;2:251-62.

24. Wald R. Anton van Dyck: Mystische Verlobung des Seligen Hermann Joseph mit Maria. Jahrbuch der Kunsthistorischen Museum Wien. 2001;2:227-40

25. Oberthaler E. Antoon van Dyck, Gefangenahme Samsons. Jahrbuch der Kunsthistorischen Museum Wien. 2001:2:240-50.

26. Fend D. Anton van Dyck: Bildnis einer Älteren Frau. Jahrbuch der Kunsthistorischen Museum Wien. 2001;2:263-5.

27. Grießer M. Untersuchungen zur Maltechnik van Dycks. Jahrbuch der Kunsthistorischen Museum Wien. 2001;2:266-80.

28. Martin E. Grounds on canvas $1600-1640$ in various European artistic centres. In: Townsend JH, Doherty T, Heydenreich G, Ridge J, editors. Preparation for painting: the artist's choice and its consequences. London: Archetype Publications Ltd.; 2008. p. 59-67.

29. Fryklund C, Lammertse F, editors. Masterpiece or copy? Two Versions of Anthony van Dyck's St Jerome with an Angel. Rotterdam: Museum Boijmans van Beuningen; 2009.

30. Alba L, Jover M, Goya MD. Introduction to the technical studies: the artistic practice of the young Van Dyck. In: Vergara A, Lammertse F, editors. the young Van Dyck. London: Thames \& Hudson; 2012. p. 337-77.

31. Eastaugh N, Walsh V. Optical microscopy. In: Stoner JH, Rushfield R, editors. Conservation of easel paintings. New York: Routledge; 2012. p. 306-17.

32. Kim NH, Hanna RB. Morphological characteristics of Quercus variabilis charcoal prepared at different temperatures. Wood Sci Technol. 2006:40:392-401

33. Lammertse F, Vergara A. A Portrait of Van Dyck as a Young Artist. In: Vergara A, Lammertse F, editors. The Young Van Dyck. London: Thames \& Hudson; 2012. p. 23-73.

34. Kirby J, Spring M, Higgitt C. The technology of red lake pigment manufacture: study of dyestuff substrate. Natl Gallery Tech Bull. 2005;26:71-87.

\section{Submit your manuscript to a SpringerOpen ${ }^{\circ}$ journal and benefit from:}

- Convenient online submission

- Rigorous peer review

- Immediate publication on acceptance

- Open access: articles freely available online

- High visibility within the field

Retaining the copyright to your article

Submit your next manuscript at $\$$ springeropen.com 